\title{
Is urologist burnout different on the other side of the pond? A European perspective
}

\author{
Karl H. Pang, MBChB ${ }^{* 1}$; Thomas E. Webb, MBBS ${ }^{* 2}$; Francesco Esperto, MD ${ }^{+3}$; Nadir I. Osman, MBChB ${ }^{+4}$ \\ 'Academic Urology Unit, University of Sheffield, Sheffield, United Kingdom; ${ }^{2}$ Department of Urology, Airedale General Hospital, Keighley, United Kingdom; ${ }^{3}$ Campus Bio-Medico, University of Rome, Rome, \\ Italy; ${ }^{4}$ Section of Reconstructive Urology, Department of Urology, Royal Hallamshire Hospital, Sheffield, United Kingdom
}

${ }^{*}$ Co-first author; ${ }^{\dagger}$ Co-senior author

Cite as: Pang KH, Webb TE, Esperto F, et al. Is urologist burnout different on the other side of the pond? A European perspective. Can Urol Assoc J 2021;15(6Suppl1):S25-30. http://dx.doi. org/10.5489/cuaj.7227

\section{Abstract}

The rate of burnout among physicians appears to be on the rise and urologist are no exception. In fact, urology appears to be one of the specialties most affected, with European urologists reporting burnout rates of up to $54 \%$ and those working in the United States up to $68 \%$.

Herein, we review the relatively few studies looking at burnout in European urologists to estimate its prevalence and discuss what could be done to reverse the trend. A total of seven studies were identified assessing burnout in urologists in Europe and Turkey. While the rates vary $(9.3-68 \%)$, they indicate that burnout is prevalent within urology, with data from other studies suggesting there is a rising trend. Although the topic has been studied for many years, with an increased focus in the last decade, little seems to have been done to improve the situation.

\section{Introduction}

Burnout among physicians is an increasing public concern. It is characterized by physical, psychological, and emotional depletion. ${ }^{1}$ The incidence of burnout appears to be highest in surgical specialties and varies among different age groups and levels of seniority. It has been shown that the incidence of burnout in urology is among the highest across all specialties. ${ }^{2,3}$ Recent comparative data suggest that the rate of burnout is equally high in Europe and the United States. ${ }^{4}$ Urology training and practice is not standardized in Europe and the incidence and risk factors vary among different European countries. The aim of this review is to discuss the prevalence, risk factors, and possible solutions to burnout from a European perspective.

\section{Method}

The PubMed database was used to identify European studies investigating burnout in urology. The following search terms were used: (burnout) AND (urology). A total of 87 articles published between January 2001 and January 2021 were retrieved from the search. Non-English articles, reviews, and conference abstracts were excluded. Overall, seven European studies were included for discussion ${ }^{4-10}$ (Table 1).

\section{The evolution of burnout}

On January 1, 2022, the International Classification of Diseases 11 th revision (ICD-11) will come into effect and it will contain the new diagnosis QD85 - Burnout. It defines burnout as "resulting from chronic workplace stress that has not been successfully managed." 11 However, the concept of burnout is not new.

The first published article on occupational burnout was in 1974 by Herbert Freudenberger. ${ }^{12}$ Maslach and Jackson later defined burnout as a syndrome of emotional exhaustion and cynicism that occurs frequently among individuals who do 'people-work' of some kind. ${ }^{1}$ They devised a tool to try and measure burnout in the form of a questionnaire, the Maslach Burnout Inventory (MBI). They divided symptoms into three dimensions: 1) emotional exhaustion (EE): feelings of energy depletion or exhaustion; 2) depersonalization (DP): increased mental distance from one's job, or feelings of negativism or cynicism related to one's job; and 3) a low sense of personal achievement (PA): a sense of ineffectiveness and lack of accomplishment. ${ }^{1}$ The $\mathrm{MBI}$ remains the primary validated tool used today.

With more and more stresses being put on health systems around the world, we are seeing that the workers themselves are starting to suffer. In 2015, Shanafelt et al looked at how burnout had increased over a four-year period. They reported that around half (54.4\%) of the 6880 U.S. workers and physicians studied exhibited symptoms of burnout in 
2014. This increased from the $45.5 \%$ reported in 2011 . Furthermore, the surgical specialties had higher rates of burnout, with urology $(63.6 \%)$ the highest. ${ }^{3}$

Burnout does not just affect the worker. While it may be easier to evaluate the cost of burnout financially, it is harder to fully equate the total impact on health services, physicians, and subsequently patient care.

We see a positive link between physician job satisfaction and patient satisfaction and quality of care. Unfortunately, there is also a link between physician dissatisfaction and patient care. ${ }^{13}$ Dissatisfied physicians are more likely to reduce their hours, leave their current position, and retire early, all of which have a negative effect on the doctorpatient relationship. ${ }^{14}$

Han et al evaluated the cost of physician burnout to healthcare systems. They estimated the cost of burnout to U.S. healthcare to be between $\$ 2.6$ billion and $\$ 6.3$ billion per year in terms of reduced turnover and lost clinical hours. ${ }^{15}$ While there may well be a financial incentive to tackle burnout among healthcare workers, there is certainly a moral one in terms of their wellbeing.

\section{Burnout in Europe}

Urologists are not exempt from burnout and recent studies suggest that rates among this healthcare population are on the rise. The Medscape National Physician Burnout, Depression \& Suicide Report 2019 found that $44 \%$ of physicians surveyed felt burned out, with urology topping the list at 54\%. ${ }^{16}$ While most of the data regarding burnout is based on our colleagues in the United States, there are more studies looking at the rates of burnout in Europe (Table 1).

\section{Germany}

In 2001, Böhle et al found that burnout was prevalent among urologists working in both the public and private settings in Germany. The study of 75 participants found that risk of burnout was associated with academic work and being $<45$ years old. ${ }^{5}$

\section{France}

In 2011, Roumiguié et al found that $24 \%$ of 186 French trainee urologists surveyed had severe burnout syndrome. In line with Böhle et al, they found that these numbers reduced with increasing age and seniority. ${ }^{6}$ These numbers were similar to those found by Gas et al in 2018 when surveying French urologists in training. They found that $24.7 \%$ of 239 French trainees reported symptoms of global burnout, defined as those with a high score in EE combined with either a high score in DP or PA, or both. Overall, $91 \%$ of all respondents had moderate impairment in relation to at least one component of the MBI. ${ }^{9}$

\section{United Kingdom}

O'Kelly et al in 2016 was the first to assess levels of burnout in urology across two different healthcare systems. They compared both consultants and non-consultant hospital doctors (NCHDs) in the U.K. and Ireland. They also tried to elucidate whether there were factors in people's dayto-day work that correlated with burnout. Critically, they also looked at how the respondents were managing or not managing their symptoms. Overall, $28.9 \%$ of the 575 urologists surveyed demonstrated high levels of burnout: $28.6 \%$ showed high levels of EE, $26.9 \%$ high levels of DP, and $31.3 \%$ high levels of PA. ${ }^{7}$ There was no difference in the rates of burnout between male and female physicians. Unlike Roumiguié et al, they noted higher levels of burnout in consultants (53.8\%) compared to NCHDs $(28.4 \%)$ in England, and those who held posts with higher levels of responsibility, with administrative workload considered a major stress factor. Interestingly, younger urologists (those aged $\leq 44$ years) had higher levels of overall burnout $(58.3 \%)$ compared to those aged 45 years and over $(46.6 \%)$. More concerning is that only $11.6 \%$ chose to characterize their work week as "constructive and productive." It is unclear why a small percentage of those surveyed reported their work week as productive, and whether this was associated with higher levels of burnout. There is an increasing amount of administrative work undertaken by urologists in the U.K., and it may be the nature of this work falling into the category of less constructive and productive, as opposed to the traditional concept that a surgeon is happiest (and possibly more productive) when seeing patients and operating.

With regards to geographic variations, the rate of burnout was significantly highest in the Republic of Ireland $(63.5 \%)$, followed by England (58.6\%), Scotland (47.3\%), Northern Ireland (45.8\%), and Wales (44\%). When questioned about managing their symptoms, $28.2 \%$ reported they required some form of treatment to combat symptoms of burnout. Only $8.2 \%$ of those surveyed have sought any form of professional help, whereas $60 \%$ would have obtained help had it been available. A total of $7.3 \%$ had required time off work for burnout, $10.6 \%$ respondents reported taking prescription medication, and $17.4 \%$ of respondents self-medicated with non-prescription medication and alcohol.? 


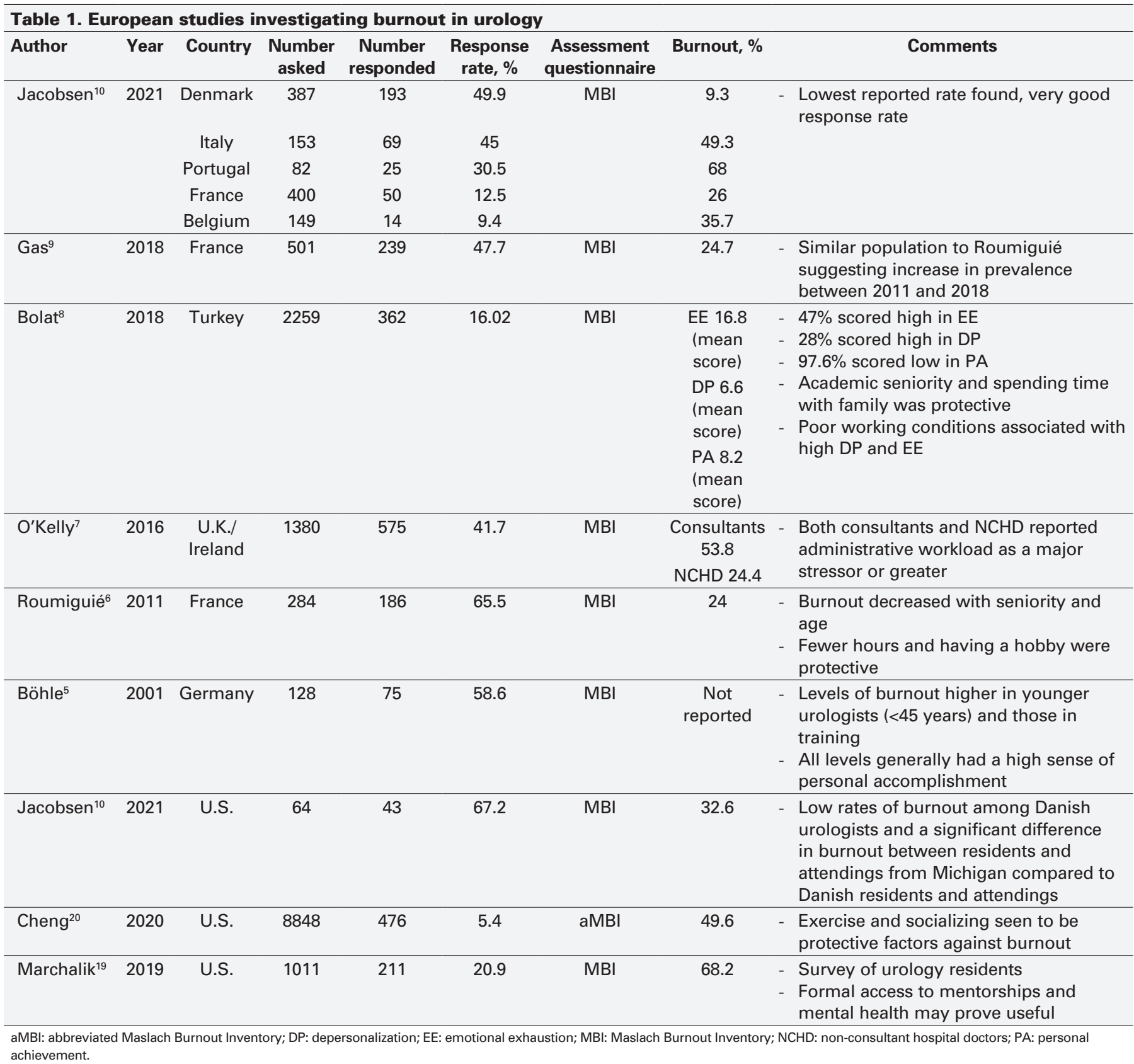

\section{Turkey}

A survey of 362 Turkish urologists assessed the three domains of the $\mathrm{MBI}$ and revealed that $47.1 \%$ and $27.6 \%$ experienced high levels of EE and DP, respectively, and $97.6 \%$ experienced low level of PA. The mean scores were 16.8, 6.6, and 8.2 for EE, DP, and PA, respectively. EE score was high in $60 \%$ of residents, $52.1 \%$ of qualified urologists, and $26.7 \%$ of professors. ${ }^{8}$ This is different to what was reported by O'Kelly et al. In the U.K. study, 40\% held a professorship/clinical lead position and $62 \%$ reported higher levels of burnout than their colleagues. ${ }^{7}$

\section{Denmark}

Jacobsen et al compared rates of burnout between urologists working in Denmark and those in Michigan, U.S. They found that again, there was a difference between rates of burnout in the two healthcare systems. The rate of burnout in physicians in Denmark was significantly lower (around 
9.3\% of 193 participants) compared with colleagues across the pond (32.6\% of the 43 surveyed). There was a statistical difference between the rate of EE, DP, and burnout among Danish residents at $3 \%, 1.5 \%$, and $3 \%$, and higher in Danish attendings at $11.1 \%, 4 \%, 12.7 \%$, respectively. ${ }^{10}$

\section{Europe in general}

Marchalik et al performed the largest study comparing burnout in urology residents in the U.S. and European systems. They defined burnout as any participant-reported "once a week" or "a few times a week" or "everyday" on the EE or DP domains of the MBI. They found that burnout was observed in $43.7 \%$ of 158 European respondents compared to $37.9 \%$ of the 211 residents surveyed in the U.S. There was also a difference between the European nations surveyed. Portuguese residents had the highest rate of burnout at $68 \%$, followed by Italy $(49.3 \%)$, Belgium $(35.7 \%)$, and France $(26 \%){ }^{4}$ The difference in the prevalence of burnout within different European countries can be attributed to several factors. The European working time directive (EWTD) requires a working week to be an average of 48 hours. However, the adherence to this varies in different European countries, and under half $(41.8 \%)$ of European trainees work under 60 hours per week. Being in a structured mentorship program was associated with lower burnout risk in Europe, and Marchalik et al reported that $22.8 \%$ of European trainees were in a structured training program. ${ }^{4}$ It is known that urology training in Europe is not standardized, with unequal distribution of time for ward, outpatient-based, and operative sessions. ${ }^{17}$ In addition, the methods used to assess clinical and operative skills are heterogenous. For example, in the U.K., trainees are expected to achieve indicative numbers in a variety of urological procedures and have to complete 40 workbased assessments per year. ${ }^{18}$

\section{Burnout in the United States}

While there is an abundance of studies regarding burnout among physicians in the United States, there are relatively few specifically looking at urology. It is clear that burnout symptoms are prevalent among urologists in the U.S., but there is some variability between the numbers reported.

One of the largest studies was conducted by the American Urological Association (AUA) in 2016. Of the 1126 respondents, $38.8 \%$ of them met their criteria for burnout. $^{2}$ This is lower than some of the more recent studies by Marchalik et $\mathrm{al}^{19}$ and Cheng et $\mathrm{al}^{20}{ }^{20}$ which reported burnout rates of $68.2 \%$ and $49.6 \%$, respectively, but from a smaller sample size.
Marchalik et al (221 responders, 20\% response rate) found that $68.2 \%$ of responders met the criteria for burnout. Of those with symptoms of burnout, $48.3 \%$ exhibited high EE, 56.9\% exhibited high DP, and 37\% exhibited both high DP and high EE. Again, seniority appeared to be protective, with $83 \%$ of interns and $73 \%$ of junior residents reporting higher levels of burnout compared to $60 \%$ of senior level residents. Understandably, working more hours was associated with higher levels of burnout. A total of $77.6 \%$ of those working $>80$ hours/week reported symptoms compared to $66.1 \%$ working $60-80$ hours and $47.1 \%$ in those working $<60$ hours. $^{19}$

Jacobsen's relatively small study of 43 urologists at the University of Michigan found similar numbers. Burnout was seen in $44.4 \%$ of residents, with $33.3 \%$ exhibiting EE and $33.3 \%$ DP. They did not detect any differences in the prevalence of burnout between male and female urologists. ${ }^{10}$

These results are broadly similar to those found by Cheng et al in 2020. While the response rate was relatively low at $6.2 \%$, there were still a relatively large number of responses $(n=476)$. The overall burnout rate (high levels of burnout in one or more domains) was $49.6 \%$. Of those identified, $40.7 \%$ reported high levels of EE, $30.7 \%$ high levels of DP, and $18.3 \%$ a low sense of PA. Being a resident or a fellow was associated with higher levels of DP and PA, and this was in line with other surgical specialties. ${ }^{20}$

\section{Comparison of burnout in Europe and the United States}

The reported differences in burnout rates across Europe and between Europe and the United States are likely due to both cultural and institutional factors. A common factor noted in studies on both sides of the Atlantic was workload and volume of administrative work. ${ }^{3,7,20} \mathrm{O}^{\prime}$ Kelly found that the top stressors for consultant urologists were an excessive administrative workload and overall work volume, representing a major stressor or greater for $43.1 \%$ and $44 \%$ of consultant urologists, respectively. Administrative workload was also the top stressor for NCHDs, with $39.4 \%$ of them reporting it as a major stressor or greater. ${ }^{7}$

Jacobsen et al created three thematic categories to try and elucidate stressors in their survey. Urologists reported "lack of time, high workload" as a stressor, with some explaining that "the number of patients they were expected to see were disproportional to the available time."10

Although hours worked was not a significant factor in rates of burnout in Europe, it was in the United States. This may be related to the EWTD in that European residents overall tended to work fewer weekly hours than U.S. 
residents: $31.8 \%$ of the U.S. and $11.4 \%$ of European residents worked more than 80 hours week, while only $8 \%$ of U.S. and $37.2 \%$ of European residents worked less than 60 hours a week. ${ }^{4}$ However, working weekends was predictive of burnout among the European cohort but not the American one. This may be due to the infrequent continuous 48 hours of work with reduced staff on a weekend. If the EWTD is adhered to, European trainees are expected to work around 8-9 hours per day. Marchalik et al also found that residents who exhibited burnout were more likely to report dissatisfaction with their work-life balance (U.S. $68 \%$ vs. $30 \%$, p $<0.001$; Europe $80 \%$ vs. $37 \%$, p $<0.001$ ) and that quality of life was significantly lower for U.S. and European residents meeting the criteria for burnout. ${ }^{4}$

\section{Limitations}

In all these studies, the data was retrospectively collected using surveys. Survey-based studies are prone to both sampling and selection bias, as well as response bias. While physicians who experience burnout might be less likely to answer any survey sent, the opposite might also be true. These surveys might present an opportunity for physicians to voice their frustrations.

There are some conflicting results too. Pruthi et al surveyed the AUA domestic membership around the same time the AUA were conducting their review of burnout. Pruthi et al's research found that out of the 733 respondents, $70 \%$ reported being satisfied, $63 \%$ reported that they would choose medicine again, and $83 \%$ said would choose urology again, with those in academic roles associated with higher levels of job satisfaction. ${ }^{21}$

\section{Solutions}

There is a need for a multifaceted approach to reduce burnout among urologists. Obviously, it is not possible to manage everything in a physician's life, but there needs to be concerted effort put into developing systems at an institutional level to improve workload and administrative burdens. Further promotion of wellness activities, such as exercise, meditation, and other alternatives should be advocated, as these have been associated with lower MBI scores ${ }^{22}$ and the absence of burnout. Additionally, multiple work-related factors, control over schedule, input into training, satisfaction with childcare, and a supportive work environment were all associated with lower burnout scores on the three scales. These factors may be used to create an improved working environment. ${ }^{23}$

\section{Discussion}

Burnout among all physicians is associated with depression, anxiety, sleep disturbances, fatigue, alcohol and drug misuse, early retirement, and suicide. Obtaining accurate figures on those affected is relatively difficult due to the methods available. As noted by O'Kelly et al, even if we were to assume a zero rate of burnout among those not responding to all the studies above, the number of those suffering from symptoms of burnout would still be significant. ${ }^{7}$ It is clear that burnout is prevalent and affects all physicians in all specialties in all countries, and there needs to be a concerted effort to try and address these issues from the top down.

A predictive factor for burnout among trainees includes not being in a structured training program. ${ }^{4}$ As discussed, the training in Europe is heterogenous and not standardized. The European Association of Urology (EAU) is attempting to bridge that gap. The European School of Urology has been running annual Resident Education Programs (EUREP) since 2007, with the aim to harmonize and standardize training across Europe. EUREP offers a platform for simulation-based training and assessment in core urological procedures. ${ }^{24}$ With regards to mentorship and support, U.K. trainees are allocated to educational supervisors and meet to discuss progression, training objectives, and any workor training-related concerns six times per year.

Another important issue identified by Marchalik et al was access to mental health services. Their study showed that readily available access to mental health services was associated with decreased burnout in the U.S. cohort, but not in the European cohort. Only $6 \%$ of European residents, as opposed to $37 \%$ of U.S. residents, reported access to mental health services. ${ }^{4}$ This finding is probably related to the cultural differences in approaches to mental health. Nevertheless, stress management programs and access to mental health services should be more available in European countries.

There is conflicting data regarding protective actions individuals can engage in to reduce levels of burnout, such as non-medical reading, yoga, exercise, and intimacy; ${ }^{3,5,6,8,8}$ however, it is important that structured programs, such as resilience training, are put in place to support individual physicians when they require it.

More needs to be done from an institutional/national level to combat burnout across all specialties. Individual stressors may vary between nations and there is scope for further evaluation of these. However, there are several factors that cross all borders; increasing hours and work-life balance are a common theme, ${ }^{2,6,10}$ along with administrative workload. ${ }^{7}$ These are all areas that likely require 
addressing at a national level rather than an individual level, particularly in nations with a formal national healthcare system. In the U.K., the British Medical Association (BMA.org.uk) offers 24/7 counselling and peer support services to all doctors and medical students, as well as their partners and dependents. In addition, all U.K. hospital trusts have access to connect with the staff health and wellbeing network.

\section{Conclusions}

Burnout is widespread among physicians throughout Europe, the United States, and no doubt throughout the world. Not only does it cost health services billions of dollars, it reduces the quality of care for our patients.

Burnout is not black and white. There are physicians who may not get the required score to be considered "burnt out" in the studies above but would still benefit from an improved working environment.

Common sense (and countless articles and textbooks) dictates that happy, well-rested, satisfied people are more likely to function at their best compared to those who are exhausted, stressed, and depressed. We need to start to move forward with initiatives to improve our fellow physicians' working lives, which in turn and equally importantly, improves the care our patients receive.

\section{References}

1. Maslach C, Jackson SE. The measurement of experienced burnout. J Organ Behav 1981;2:99-113. https://doi.org/10.1002/job.4030020205

2. North AC, et al. Burnout in urology: Findings from the 2016 AUA annual census. Urol Pract 2018;5:48994. https://doi.org/10.1016/i.urpr.2017.11.004

3. Shanafelt TD, Hasan 0 , Dyrbye LN, et al. Changes in burnout and satisfaction with work-life balance in physicians and the general US working population between 2011 and 2014. Mayo Clin Proc 2015;90: 1600-13. https://doi.org/10.1016/i.mayocp.2015.08.023

4. Marchalik D, Goldman CC, Carvalho FFL, et al. Resident burnout in USA and European urology residents: An international concern. BJU Int 2019;124:349-56. https://doi.org/10.1111/bju.14774

5. Böhle A, Baumgärtel M, Götz ML, et al. Burn-out of urologists in the county of Schleswig-Holstein, Germany: A comparison of hospital and private practice urologists. J Urol 2001; 165:1158-61. https://doi.org/10.1016/S0022-5347(05)66454-3

6. Roumiguié $M$, Gamé X, Bernhard IC, et al. Les urologues en formation ontills un syndrome d'épuisement professionnel ? Évaluation par le Maslach Burn-out Inventory (MBI). Prog en Urol 2011;21:636-41. https://doi.org/10.1016/i.purol.2011.02.006
7. O'Kelly F, Manecksha RP, Quinlan DM, et al. Rates of self-reported 'burnout' and causative factors amongst urologists in Ireland and the UK: A comparative cross-sectional study. BJU Int 2016;117:36372. https://doi.org/10.1111/bju.13218

8. Bolat MS, Yürük E, C, Inar 0 , et al. The prevalence of burnout syndrome among Turkish urologists: Results of a nationwide survey. Turk J Urol 2018;1-8. https://doi.org/10.5152/tud.2018.34202

9. Gas J, Bart $S$, Michel P, et al. Prevalence of and predictive factors for burnout among French urologists in training. Eur Urol 2019;75:702-3. https://doi.org/10.1016/i.eururo.2018.12.037

10. Jacobsen FM, Jensen CFS, Schmidt MLK, et al. Burnout among urologists from Denmark and Michigan. Urology 2021;147:68-73. https://doi.org/10.1016/i.urology.2020.07.066

11. World Health Organisation. ICD-11. Mortality and morbidity statistics. (2020). Available at: https://icd.who.int/browsel 1//-m/en\#/http://id.who.int/icd/entity/129180281. Accessed Jan. $24,2021)$

12. Freudenberger HJ. Staff burnout. J Soclssues 1974;30:159-65. https://doi. org/10.1111/j.1540-4560.1974.tb00706.x

13. Shanafelt $T D$, Balch $C M$, Bechamps $G$, et al. Burnout and medical errors among American surgeons. Ann Surg 2010; 251:995-1000. https://doi.org/10.1097/SLA.0b013e3181bfdab3

14. Shanafelt T, Sloan J, Satele D, et al. Why do surgeons consider leaving practice? J Am Coll Surg 2011;212:421-2. https://doi.org/10.1016/i.jamcollsurg.2010.11.006

15. Han $S$, Shanafelt TD, Sinsky CA, et al. Estimating the altributable cost of physician burnout in the United States. Ann Intern Med 2019;170:784-90. https://doi.org/10.7326/M18-1422

16. Kane L. Medscape national physician burnout, depression \& suicide report 2019. Available at: https://www.medscape.com/slideshow/2019-lifestyle-burnout-depression-601 1056. Accessed Jan. 24, 2021.

17. Carrion DM, Rodriguez-Socarrás ME, Mantica G, et al. Current status of urology surgical training in Europe: An ESRU-ESU-ESUT collaborative study. World I Urol 2020;38:239-46. https://doi. org/10.1007/s00345-019-02763-1

18. JCST. Joint Committee on Surgical Training: Cerrification guidelines for urology. (2017). Available at: https://www.jst.org/quality-assurance/certification-guidelines-and-checklists/. Accessed Jan. 24, 2021.

19. Marchalik D, Brems J, Rodriguez A, et al. The impact of institutional factors on physician burnout: A national study of urology trainees. Urology 2019;131:27-35. https://doi.org/10.1016/i.urology.2019.04.042

20. Cheng JW, Wagner $\mathrm{H}$, Hernandez BC, et al. Stressors and coping mechanisms related to burnout within urology. Urology 2020;139:27-36. https://doi.org/10.1016/j.urology.2019.11.072

21. Pruthi RS, Deal A, Langston J, et al. Factors related to job satisfaction in urology. Urol Pract 2016;3:16974. https://doi.org/10.1016/i.urpr.2015.06.001

22. Eckleberry-Hunt J, Lick D, Boura J, et al. An exploratory study of resident burnout and wellness. Acad. Med 2009;84:269-77. https://doi.org/10.1097/ACM.0b013e3181938045

23. Degheili J, Yacoubian A, Dargham R, et al. Burnout of residents: Overview from various medical institutions — a suggested model for improvement. Urol Ann 2020;12:9-14. https://doi.org/10.4103/ UA.UA_107_19

24. Somani BK, Van Cleynenbreugel B, Gozen A, et al. The European Urology Residents Education Programme hands-on training format: 4 years of hands-on training improvements from the European School of Urology. Eur Urol Focus 2019;5:1152-6. https://doi.org/10.1016/i.euf.2018.03.002

Correspondence: Dr. Karl H. Pang, Academic Urology Unit, University of Sheffield, Sheffield, United Kingdom; karlpang@doctors.org.uk 